\title{
Knowledge Management in Law Firms
}

\author{
Stefane M. Kabene, M.Ps., Ph.D. \\ Philip King, LL.B., M.B.A. \\ Nada Skaini, B.M.O.S. \\ The University of Western Ontario \\ London, Ontario \\ Canada
}

\section{Abstract}

Traditional methods of managing human capital, innovation, and learning within organizations, particularly law firms, have proven ineffective as they often fail to contribute to a firm's success. Over the last few decades, the rise of a knowledge-based economy has precipitated the need for management of such intangible assets, as they often signify a company's competitive advantage. This paper examines knowledge, knowledge management, their impact on law firms, and the role of human resources throughout the knowledge management process. The results of this study demonstrate the importance of human resources in the implementation and direction of knowledge management. Human resources (HR) is required to generate an organizational culture of knowledge sharing through the implementation of policies and reward systems, including pay-for-knowledge. HR will also need to ensure person-to-person contact through Communities of Practice, mentoring programs and daily contact. Ensuring support and commitment on behalf of the senior management team is imperative for effective execution of knowledge management. The implementation of knowledge management systems will enable firms to thrive in the face of today's rapidly changing economy and will further contribute to the development of sustainable competitive advantages. The scope of this paper is to examine what human resource professionals can do, and describe how human resources management can play a critical role, in ensuring the successful implementation of knowledge management within law firms.

The main objective of this paper is to establish and analyze the importance of knowledge management (KM) in today's law firms. Throughout this paper, the concepts of knowledge and KM will be explored in detail, with an emphasis on their roles within law firms. Knowledge and $\mathrm{KM}$ are increasingly important issues for human resources management, and they are particularly amplified in law firms compared to other industries.

\section{Introduction}

Currently, individuals are bombarded with knowledge. Bontis (2000) believes that by the year 2010, the world's codified knowledge will double every 11 hours. Not only is the production of knowledge increasing but the rate of knowledge production itself is increasing (Laszlo, 2002, p.5). The assumption that the concept of knowledge is fundamental to comprehending organizations is reflected through the emphasis of an organization's competencies and 
knowledge as being crucial to its strategic performance (Madhavan, 1996, p.4). As we enter an information era, there is an abundance of knowledge available, though the management of it appears less than satisfactory. The poor organization of knowledge within firms prevents these firms from benefiting financially and/or socially.

During the last few decades, we have witnessed a growth in the discussion and significance of knowledge; focusing on the concept and application of KM within the rise of knowledge-based organizations. According to Gold (2001) the infrastructure for successful KM consists of a flexible organizational culture, up-to-date and supportive technology, and a solid corporate structure.

Although the implementation of KM is crucial to the enhancement of many firms within various industries, it is uniquely essential to law firms as it offers a competitive advantage that is not easily replaced or imitated.

The following are four major questions we seek to answer in this paper:

1. What is knowledge?

2. What is KM?

3. Why is KM important to law firms?

4. What are some solutions and strategies available to law firms to deal with these issues?

\section{Knowledge, Data and Information}

\subsection{Knowledge}

Knowledge is most commonly defined as what we know. It involves 'the mental processes of comprehension, understanding and learning that go on in the mind, however they also involve interaction with the world outside the mind, and interaction with others' (Wilson, 2002, p.2) Vat (2003) believes that knowledge is intriguing as it is always open to interpretation, is constantly changing, and is constructed over time. Although the creation of knowledge is not merely a compilation of facts, it is a uniquely human process that cannot be easily replicated.

\subsection{Data and Information}

In order to fully understand the depth of knowledge, we must differentiate it from data and information. According to Gomes (2001) data are 'simple facts and figures out of context that are, therefore, not directly meaningful.' In order for the firm to consider data useful, it must be processed into information by connecting it to a context. Gomes (2001) thus believes that information is defined as organised facts and data, which are converted into context for specific use. 


\subsection{Knowledge as Capital}

The significant difference between information, data and knowledge is that knowledge always contains a human factor, as it is regarded as something individuals possess. It has always been the main contributing factor, in the business world, to the good performance of a firm. Gomes (2001) strongly believes that knowledge is an asset and should be managed, in a similar fashion to the traditional cash flow, human resources, or raw materials. The concept of knowledge as an 'intangible asset' is growing in popularity and value within our knowledge-based economy.

By the end of the 1990s, references to intellectual capital in business were commonplace (Bontis, 2000, p.5). Intellectual capital is generated within one's intellectual space. Each member of an organization possesses his or her own knowledge space, which is subject to some level of description and may be 'architected, integrated, and designed into an organization' (Vat, 2003, p.1). In accordance with Vat (2003), as the source of a firm's wealth shifts from tangible assets to knowledge, it is evident that firms who create their own communal knowledge space between their members will embrace a great advantage over those who choose not to. The same belief can be, and is, applied to firms. In order to benefit from and develop a communal knowledge space, one requires a context for knowledge fusion, which should aid in the structure and facilitation of knowledge implementation and interconnectivity within a firm (Vat, 2003, p.7).

\subsection{Explicit and Tacit Knowledge}

The framework for organizational knowledge creation according to Vat (2003) includes the dynamic interaction between the known (explicit knowledge), cultural knowledge, and the vision (tacit knowledge), all products of human experience and reflection. Explicit knowledge is easy to articulate and communicate, therefore making it less complicated to transfer between individuals and organizations (Madhavan, 1006, p.2). Cultural knowledge consists of assumptions, beliefs and values that are used to construct reality and to assign significance to new information and knowledge (Choo, 1999, p.2). However, it is the role of tacit knowledge that is becoming increasingly important in firms. Gomes (2001) views tacit knowledge as highly personal and difficult to formalise and communicate to others, as it is context-dependent. Since tacit means unspoken, tacit knowledge is hidden, sometimes even from the consciousness of the 'knower' (Wilson, 2002, p.18). A major challenge that firms encounter is transforming their tacit knowledge into explicit knowledge. A great deal of organizational knowledge remains tacit as it cannot be efficiently explained using formal language, and because it is unfeasible to describe all aspects necessary for success and performance (Madhavan, 1996, p.7). Firms have discovered that the innovation and application of tacit knowledge contributes to one's competitive advantage, especially during a time in which information transformed into knowledge is progressively more valuable and more powerful than ever before.

\section{Employees, Knowledge, and Learning}




\subsection{EMPLOYEES AND KNOWLEDGE}

In relation to Huizing (2000), oftentimes, those who seek information have difficulties finding correct information sources, reaching sources, and assessing the quality and reliability of the sources. Similarly, those who provide information are frequently unaware of those whom their information could benefit, and therefore fail to share or store that information. It is not only important to determine what types of knowledge and information are available, but with whom that knowledge and information resides.

Huizing (2000) argues that to maintain a communal knowledge space, people must be motivated to contribute to such systems and be available for information seeking colleagues. There must be arrangements within firms for knowledge transfer infrastructures in attempts to encourage human interaction. Although knowledge from others may enlighten individuals' thinking, it cannot replace it.

\subsection{LEARNING}

Learning has become one of the main sources of sustainable competitive advantage, which explains the growing awareness of knowledge. Trends indicate that global challenges require the need for evolutionary learning and the empowerment of 'learners'- those individuals competent in generating new knowledge and processes as responses to changing environments (Laszlo, 2002, p.407). As a result of increased global competition, as well as the substantial amounts of shared information, firms are forced to increase their capacity to learn if they wish to function successfully within today's market. Laszlo (2002) depicts learning through collaboration, or 'organizational learning,' as an essential aspect for knowledge creation and innovation. Garud (1997) proposes the concept of 'know-how', an idea that widely represents knowledge, and is shaped by a process of 'learning-by-doing.' This process entails knowledge enhancement through the performance of tasks accumulated through experience over time. This is particularly important as experience is becoming a more valuable commodity in the eyes of many companies, often more valuable than one's formal education. Although learning processes within firms have improved, history has demonstrated the lack of sufficient learning from past experiences, as well as inefficient preservation of fundamental knowledge from the present (Laszlo, 2002, p.407). This implies, and is a reason for the development of new forms of learning and KM.

\subsection{Trends Affecting Knowledge}

In today's corporate world, knowledge and the processes to generate and manage it have proven to be significant sources for establishing a competitive advantage. According to Neidorf (2002), the exposure of information and knowledge represents one of the key ways in which individuals and firms maintain their position and status within the corporate hierarchy. However, the types of knowledge relevant to the development and maintenance of a competitive advantage has transformed over time. As a result of increased competition and globalization, Laszlo (2002) conveys that companies are forced to focus beyond the enterprise itself in order to learn more about external factors, such as competitors. The main source of value creation has evolved from 
'knowledge and the processes of its acquisition, generation, distribution and utilization' (Laszlo, 2002, p.401). Thus, valuable firms are those that consistently create new knowledge, distribute it throughout the entire organization, and quickly embody it in new technologies and products.

The relevance of knowledge and the need for procedures to manage it first became visible in the business world. The design of suitable information systems is mandatory so that individuals with knowledge can perform the functions necessary to produce valuable results to the firm. The study of KM evolved from the need to control resources more successfully in a 'hypercompetitive, global economy' (McCampbell, 1999, p.173). In order for knowledge to be put to good use for human development, we must control the processes through which knowledge is created, stored, shared, and used. The importance of these processes brought about the establishment and eventual awareness of the concept of KM.

\section{Knowledge Management}

The business environments in which organizations compete are continuously changing. The movement from a post-industrial to a knowledge-based economy has radically altered the ways in which companies conduct business. The knowledge-based economy in which organizations participate is one that places an enormous amount of value on intellectual capital.

Organizations and HR professionals continuously focus their efforts on attracting the best employees who possess an abundance of knowledge and skill in order to enhance the overall value of the company. Companies then invest large amounts of capital to further increase employees' knowledge, via training and continuous education programs. At the same time, the emerging knowledge-based economy encourages individuals to be more self-seeking in their career objectives and aspirations. Employees are now playing a more consultative role within organizations. New age employees are expected to work for multiple companies and have multiple careers over their lifetimes. In this environment, there is a more egocentric view of knowledge; knowledgeable workers protect their assets and dedicate themselves to lifelong learning, not just for the benefit of their employers, but for themselves in order to remain marketable and indispensable. Thus, the individual knowledge worker and the organization determine the value of knowledge with each holding a different perspective. As a result, the need for firms to focus on KM grows.

$\mathrm{KM}$ is an emerging discipline and is a multifaceted concept, therefore, much like 'knowledge,' it varies in definition. The definition of $\mathrm{KM}$ is to some extent a work in progress, much like the field itself. '[I]n discussing knowledge management and exploring its potential, participants will present a view of what knowledge management is for their organization, which will frequently be challenged by others who have a different, but equally valid view' (Binney, 2001, p.34). Although there is a plethora of different definitions, models and variations on the topic, the basic premise remains the same: KM facilitates the transfer of knowledge throughout an organization.

Considering organizations are composed of people from varying disciplines, KM systems provide an adequate method to facilitate communication and collaboration between employees 
who may not normally communicate but are able to offer distinct knowledge to others. In this respect, KM systems help connect an organization. McCampbell (1999) notes that for the transfer of knowledge to be effective, it depends on the presence of teams, relationships and networks. It is difficult to dispute the benefits teamwork provides, as it often results in innovative thinking - an asset crucial to any firm (Binney, 2001, p.37).

\subsection{Model of Knowledge Management Capabilities and Effectiveness}

Knowledge is a product of understanding information and data. Therefore, KM encompasses Data Management and Information Management (Nguyen, 2002, p.20). The structure of KM consists of two primary components: knowledge infrastructure and knowledge processes.

\section{A. Knowledge Infrastructure}

A firm's knowledge infrastructure capability is realised via technology, organizational structure, and culture. These three elements enable knowledge transfer and successful KM. They are the pillars of a firm; what keeps it standing.

\section{Technology}

The technology element explores whether the company has the appropriate software and equipment needed to maximise their potential to transfer as well as the potential 'needed to mobilise social capital for the creation of new capital'(Nguyen, 2002, p.20). McCampbell (1999) notes Information Technology as the key enabler for the implementation of KM. Consequently, technology makes knowledge sharing feasible, especially within large organizations where direct contact is difficult. Technology is the vehicle that satisfies a company's need for accessibility, speed and efficiency in collecting and accessing knowledge.

\section{Organizational Structure}

The importance of organizational structure proposes the question: does the organization have the right employees and positions required to transmit knowledge in an optimal manner? KM theorists suggest that flexibility and non-hierarchal structure are the best environmental factors for implementing a KM system (Gold, 2001, p.71). In addition, a company must have sufficient reward programs that motivate employees to share their knowledge with the rest of the firm.

\section{Culture}

Lastly, the cultural element of knowledge infrastructure explores the degree to which the organization's corporate culture promotes the transfer and sharing of knowledge. Maintaining an effective corporate culture is arguably the most significant determinant in the success of a KM program. Without a culture that is conducive and supportive toward sharing, any KM system will inevitably fail. In order to promote an adaptable corporate culture, great emphasis must be placed on the importance of knowledge. Gold (2001) suggests four primary mechanisms that stress the importance of knowledge sharing within an organization: organizational culture, 
employee interaction, corporate values and management support. It is extremely important to have management support when implementing any type of strategic program. If management lacks the dedication and support toward a KM program, employees may misinterpret this behaviour and view knowledge sharing as unimportant, thus exerting minimal effort. A company's success at shaping its culture will help enhance its ability to manage knowledge more effectively (Davenport, 1998, p.56).

\section{B. Knowledge Process Capability}

The second component in understanding KM is the knowledge process capability. An organization's knowledge process capability consists of four elements: acquisition, conversion, application and protection. Acquisition refers to the collection and obtainment of information and data, while the conversion process is the transformation of information and data into usable knowledge. The application process refers to knowledge that is accessible for use as well as the knowledge that is put to use. Lastly, the element of protection is to ensure that knowledge is protected from outsiders so that it remains a competitively advantageous asset to the company (Gold, 2001, p.67-84).

Knowledge and information are intangible assets. The characteristic of knowledge as intangible creates the need for process capabilities. Processes are applied in order to transform elicited knowledge into document form, which is referred to as a knowledge artefact (McInerney, 2002, p.14). 'In a knowledge management program, objects or artefacts usually reside in an electronic repository of some kind so that all members of an organization can have access to the knowledge they represent' (McInerney, 2002, p.15). This demonstrates how knowledge infrastructures and processes coexist; technology is what enables the application process to access knowledge. Therefore, the success of a KM program depends on how competently a company develops and utilises both its knowledge infrastructure and its knowledge processing capabilities.

\subsection{Application of Knowledge Management}

There exist many interpretations of KM; however, Binney (2001) delivers a superior summary on the methods of KM application. He categorised KM applications into six elements: transactional, analytical, asset management, process based, developmental, and innovation/creation KM.

\section{Transactional}

Transactional applications of KM systems encourage employees to complete transactions as well as increase accessibility and tracking of knowledge. This function aims to improve a company's customer service operations, order accuracy, and service agent support applications.

\section{Analytical}

Analytical KM offers interpretations of knowledge and data. Examples of analytical applications are Management Information System, Customer Relationship Management, and Decision 
Support Systems. These systems transform large amounts of data in order to discover information trends and patterns; thus if applied and understood could possibly become knowledge.

\section{Asset Management}

The asset management function of KM is concerned with managing codified explicit knowledge or intellectual property. Applications of asset management consist of document management, knowledge valuation and knowledge repositories (storage).

\section{Process-based}

Process-based KM is concerned with the codification and improvement of processes. Examples of programs that assist with this application are Total Quality Management, Business Process (Re)-engineering, and Process Automation.

\section{Developmental}

Developmental KM applications focus on improving knowledge workers' competencies and capabilities by increasing the accessibility and sharing of knowledge. This includes skill development, teaching and training.

\section{Innovation and Creation}

Innovation and creation KM applications concentrate on creating environments where workers, possessing various disciplines can collaborate to create new knowledge and innovation. Applications for innovation KM involve networking, team work (including virtual teams previously geographically separated), discussion forums and communities.

One can see that there are various methods and ways that KM can be applied. The usefulness of each application, and the corresponding technologies used, vary from organization to organization.

\subsection{Success and Benefits of Knowledge Management}

The benefits of KM are endless. If KM is implemented successfully in congruence with organizational structure and culture, it can constitute a sustainable and equitable source of competitive advantage, an opportunity to differentiate, a cost advantage, and even the key to organizational survival. In essence, KM enables firms to build capacity by better accessing the assets that they already have with more efficiency.

\section{Knowledge Management in Law Firms}


Stemming from the legal system and practices of ancient Mesopotamia, written law has been apparent in many societies around the world for centuries. From the Code of Hammurabi, to the modern law reports that appear on the Internet, the idea of law has helped to shape cultural beliefs and values. Historically, the practice of law has been a practice of knowledge and skills that requires the accurate, effective and objective use of information (Lambe, 2003). Today, law firms face an increasingly competitive market due to increased specialization and a need to compete globally (Falkin, 2002, p.2). Among other things, these forces have reiterated the value of knowledge within the industry. According to Lambe (2003), 'most large law firms recognise that they are in a knowledge business, and they too suffer from the challenges of connectivity, globalization and speed.' As a result, major law firms must share knowledge more efficiently and more effectively than ever before. In order to do so, many law firms are turning to KM for a solution (Buckler, 2004).

\subsection{The Law Firm}

In order to fully realise the advantages of KM within the industry, it is essential to understand the structure of law firms, the stakeholders involved, and the motivation behind the creation of a law firm. According to Khandelwal and Gottschalk (2003), law firms are similar to social communities which specialise in speed and efficiency in creating and transferring legal knowledge. When this statement is broken down into separate components and examined further, it exemplifies the 'ideal' firm. The ideal firm consists of a community of individuals who create and transfer knowledge quickly and efficiently. Unfortunately, because of the stakeholders involved, this is not always the case. As Hunter (2002) notes, a law firm is generally composed of lawyers, paralegals, managers, support personnel and administrators. These diverse occupations have distinct functions, yet these individuals must work together to achieve the desired outcome of adding value to the firm. It is also important to note that, depending on the size of the law firm, its organizational structure may vary significantly. However, Hunter (2002) also states that each law firm has a unique set of distinct characteristics and operating procedures that can play an important role in the creation and implementation of a KM strategy.

To understand the reasons why KM is such an important business driver, it is essential to be aware of the scope and purpose of a law firm. A firm's mission statement can be useful in providing a clear and accurate snapshot of both the scope and purpose of the firm. In general, the mission statement of a professional service firm provides three main objectives: to deliver outstanding client service, to provide fulfilling careers and professional satisfaction to employees and to achieve financial success to grow (Hunter, 2002, p.8). These three objectives can have a major impact on the decision to implement a KM program.

According to Southon (2002), a firm must have access to the best minds and therefore the best knowledge in their chosen fields to provide outstanding client service. Terrett (1998) asserts that this includes such things as clear and timely billing, an ability to respond to the unexpected, and an ability to create innovative solutions. KM can play an important role in achieving these objectives because it has the potential to increase efficiency and effectiveness within the firm. 
In addition, providing professional satisfaction to employees is essential because employees who are not learning and those who are engaged in repetitive tasks will get bored, grow disillusioned and eventually leave the firm (Terrett, 1998, p.72). This employee turnover may have a devastating impact on the future success of a law firm because, by losing the tacit knowledge that these employees bring to the team, the firm also loses value and compromises its ability to accomplish its mission.

The final objective of professional service firms in Terrett's (1998) view is that they demand financial success and growth. This depends on a number of factors including the market in which they compete and the range of services they provide. KM can thus be an enabler to financial success and growth.

Finally, the most important part of any law firm is its lawyers. According to Khandelwal and Gottschalk (2003), lawyers can be viewed as professionals who have gained knowledge explicitly and tacitly through formal education learning on the job respectively. Although all lawyers have received the explicit knowledge needed to practice law, what really differentiates one lawyer from another is the tacit knowledge or experience they have gained from practicing (Kofoed, 2001, p.9). The sharing of tacit knowledge among lawyers is the single biggest knowledge related issue in a law firm.

\subsection{Issues That Law Firms Need To Address}

The demand for KM in law firms is derived from the following four inter-related areas:

$>$ Efficiency

$>$ New competition

$>$ Poor communication

$>$ Retirement

It is important that law firms address these issues in order to ensure the growth and sustainability of their practices.

\subsubsection{Efficiency}

Primarily due to the way lawyers are compensated, there is much debate over whether or not capturing efficiencies can actually benefit the firm. According to Becker et al. (2003), 'client loyalty is decreasing as companies increasingly base purchases of legal services on a more objective assessment of their value, defined as benefits net of price.' Analogous to many other industries, increased competition has forced some law firms to compete in price wars. As a result, certain services are currently being offered at much lower prices (Dublin, 2005). Although prices must remain competitive, the quality of work provided must continue to meet the expectations of customers. Based on this assessment, law firms must capture efficiencies in their practices in order to compete in the market (Hunter, 2002, p.7). As mentioned before, the main problem with capturing efficiencies in the law market is that there can be a number of negative repercussions on both employees and the bottom line. These repercussions are mainly attributed to the incentive structure of law firms and how clients are charged based on billable hours (Kay, 
2003, p.4). Although this is a major issue that law firms must address, there are a multitude of options that make good strategic business sense.

First of all, Dublin (2005) notes that research in a law firm is often duplicated by a number of lawyers meaning agreements, memoranda and other documents may be created from scratch when adequate models for such documents already exist. Dublin (2005) also states, 'the concern is not just inefficiency but also the inability to take advantage of best practices and current information and to make proper assignments to people with appropriate experience.' This is an important issue because the costs associated with neglecting to assign the appropriate work to the appropriate people can have a negative effect on efficiency within the firm and can result in lost or misplaced knowledge (Khandelwal \& Gottschalk, 2003, p.9). Other consequences of such action include wasted time and poor quality work. Although most law firms have implemented programs that attempt to standardise their practices, they still have a long way to go before their practices are efficient.

According to Khandelwal and Gottschalk (2003) law firms are increasingly being pressured by their clients to achieve productivity gains through the use of technology to become more efficient. This problem is magnified because so many other businesses are achieving productivity gains through the use of technology. Furthermore, 'business clients expect law firms to have certain technologies in place and are not willing to pay lawyers to deliver work in what is seen as inefficient and expensive ways' (Dublin, 2005). As clients become increasingly frustrated with the inefficient practices of lawyers, both tangible and intangible costs will result (Lambe, 2003). The most devastating cost associated with frustrated clients can be the loss of future business, which can have an overwhelmingly negative effect on profitability.

\subsubsection{New Competition}

Another important issue that law firms must address is new competition in the industry. Among other things, this can be attributed to globalization. According to Becker et al. (2003), global companies increasingly seek out law firms that provide continuous support for all business locations. Regardless of the size of the law firm, globalization can have a major effect on the sustainability of the firm.

As KM is considered to be a key success factor, it is important for law firms to differentiate themselves based on their competitive advantages - their knowledge workers (Gottschalk, 2002). Consequently, it is becoming increasingly difficult to attract the best minds in the industry. As stated by Dublin (2005), a new generation of lawyers exists who are oblivious to life without the internet. It is therefore increasingly important that firms remain on top of the latest information technologies in order to facilitate knowledge transfer and thereby recruit the best graduates, who have come to expect such capabilities in a modern law firm.

\subsubsection{Poor Communication}

A third major issue that law firms need to address is the problem associated with communications within the firm. Knowledge transfer 'inside or outside the firm occurs by happenstance or though one-on-one conversations without a sharing of information by all who 
need the information' (Dublin, 2005). The lack of sharing knowledge effectively has negative effects on productivity, which may lead to inefficiencies.

According to a study by Khandelwal and Gottschalk (2003), teamwork is generally not rewarded in firms with an overwhelmingly busy senior staff who cannot reflect on their experiences. Being unable to share valuable information may have a number of negative consequences. The information itself may be lost, or may be possessed by a single individual whose contribution to the firm may be lost through death, disability or retirement. Additional time and expense may be required in order to extract the information from those who possess it, creating inefficiencies and unnecessary delay. Law firms must encourage and enable efficient internal communication mechanisms if they are to benefit from KM.

\subsubsection{Retirement}

Finally, retirement is arguably the most important human resource issue in a law firm. Due to the increasing number of senior lawyers that are approaching the age of retirement, valuable information will be lost if their experience and expertise is improperly documented. The major issue here is that the tacit knowledge these professionals have gained throughout their careers will be lost if it is not properly captured before their employment is terminated (Carine, 2003, p.4). Every time a firm loses an older lawyer to retirement, the value of the firm decreases and it becomes less competitive in the marketplace. It is therefore highly desirable to transfer the knowledge and wisdom of older lawyers to younger lawyers (Dublin, 2005). This knowledge must be captured and stored in a useable fashion in order to gain the competitive advantage that such knowledge represents.

\subsection{Advantages of Knowledge Management in a Law Firm}

The following list of advantages outlined by Stuart Kay (2003) may be implemented in a KM program of a law firm:

- KM will allow a firm to produce certain documents more efficiently thus resulting in a higher level of service.

- If specialist knowledge is captured in a document or system, it will allow a firm to give higher quality of service to their clients.

- Good KM makes life much easier for lawyers and can result in increased productivity and reduced stress.

- Capturing knowledge in a system allows it to remain if an individual leaves the firm.

- Good KM aids in the transfer of knowledge between lawyers, thus ensuring knowledge is retained and made available for re-sale

- Effective KM can assist in the integration of new lawyers into the firm.

- $\mathrm{KM}$ is a necessary component of risk management. Effective transfer of knowledge may help avoid professional negligence suits. 
For these reasons, if a firm wants to survive and prosper in a competitive market, it is essential that they implement a KM program. According to Kay (2003), KM allows lawyers to be more effective and productive lawyers who provide better service to their clients.

\subsection{Barriers to Knowledge Management in a Law Firm}

While the advantages of employing a KM program in a law firm should now be obvious, there are many barriers that a firm must overcome before a KM program can be successfully implemented. These barriers have been ingrained into the profession over a long period of time and tend to be very significant hurdles. As a result, vendors of data mining, KM and other information technologies are often disappointed by the resistance they meet when trying to sell KM services to law firms (Dublin, 2005).

\subsubsection{Culture of Individual Practices}

By nature, law firms tend to foster a culture of individual practices. Lambe (2003) defines it as an exclusivist profession which obtains value from being able to organised specialised knowledge that is not readily accessible. However, the notion of individual practices is also inherent in the law profession itself. From the first day on the job, lawyers are encouraged to be client focused (Terrett, 1998, p.74). This can be attributed to the fact that the tacit knowledge possessed by individual lawyers is sold to clients and is therefore translated into revenue. One of the major obstacles in implementing KM practices in law firms is that there exist few financial incentives for lawyers to share knowledge with their colleagues. This problem is magnified by the fact that the primary source of a lawyer's income is derived from time spent, which time is generally spent with clients (Lambe, 2003). Therefore, lawyers are not typically recognised for adopting a team-based approach to legal work nor are they rewarded for sharing their expertise. This tendency is demonstrated in large litigation projects where each lawyer takes responsibility for a particular area (Terrett, 1998, p.74).

The notion that a law firm is a place that supports and fosters a culture of individual practices has been amplified by the fact that clients often hire individual lawyers based on reputation.

According to Terrett (1998), 'clients increasingly want to hire individual lawyers and will often pay a premium to ensure that a 'star' works on their particular matter.' Although most law firms would like to think that clients hire lawyers based on the firm's credentials, this is not often the case. This culture of individual practices will remain unless knowledge workers begin to share information.

\subsubsection{Resistance to Technology}

Resistance to technology is another major barrier to the use of KM practices in law firms. Older lawyers may be reluctant to transfer their knowledge to younger lawyers because of discomfort or unfamiliarity with the use of technology (Dublin, 2005). It is difficult to introduce new modes of thinking into a firm that is currently successful and that has been successful for a long period of time using traditional practices. As a result, new ideas are often met with resistance from those whose support is needed the most (Terrett, 1998, p.73). Lawyers who have been successful for a 
number of years using traditional practices may be averse to change because they may not recognise the potential benefits of KM or the importance of knowledge transfer.

According to one study, even lawyers whose careers show a demonstrated ability to learn completely new areas of knowledge during the preparation of cases or through their representation of clients in a particular industry will completely dismiss the notion of using computers. This reluctance to learn even the basics of information technology may result in an unwillingness to be involved in 'technology' at any level (Dublin, 2005). The implications associated with the reluctance of older attorneys to share information through the use of technology can be devastating to a firm. As discussed above, if knowledge is not captured properly it can be easily lost.

\subsubsection{Lack of Time}

One of the major barriers of integrating $\mathrm{KM}$ into a law firm is that lawyers generally do not have time to input their knowledge into computers. Furthermore, the increasing emphasis on billable hour requirements tends to leave lawyers with little time and opportunities for anything other than direct client service (Terrett, 1998, p.75). Implementation of KM in law firms is difficult because it requires the investment of substantial amounts of lawyer time. Therefore, systems that require a great deal of time spent inputting information have little chance of success in most law firms (Dublin, 2005). Time spent sharing knowledge and experience is time not spent billing clients (Terrett, 1998, p.75). Therefore, law firms must develop incentives in order to persuade lawyers to spend time documenting the knowledge they possess.

\subsubsection{Inability to Measure Returns}

One of the more interesting barriers to $\mathrm{KM}$ in a law firm is the inability to measure returns. In many firms, KM capabilities and benefits are not properly measured because the metrics required to measure the financial returns are not readily available. However, if billing structures are not changed, the efficiencies obtained through KM may not benefit a firm financially (Kay, 2003, p.1). According to Dublin (2005) this is because, provided billing continues to be based on an hourly basis, reducing the amount of time spent on any given task would not be advantageous to the overall profitability of a firm.

\subsubsection{Incentive Structure}

Finally, the incentive structure used by most law firms inhibits the use of KM systems. In certain cases, Dublin (2005) notes that lawyers may be penalised for their efforts at knowledge transfer, if it has the effect of reducing their billable hours. Furthermore, in a traditional law firm, there is often no incentive structure that will motivate lawyers to involve themselves in a KM project. The lack of incentives, coupled with a tendency to dismiss the notion of KM rather than analyze where the previous projects have failed and develop effective new projects, can create a number of inefficiencies within a firm. Consequently, if the incentive structure of a law firm does not encourage the sharing of knowledge, Terret (1998) believes the existence of a knowledge marketplace could be hidden and possibly lost forever. 


\section{Discussion}

As a result of the research, it has been determined that in order for KM to be successfully implemented, attention must be focused on six areas: Culture, Trust and Loyalty, Communities of Practice, Role of Human Resources, Motivation and Rewards for employees and the Role of Technology.

\subsection{Culture}

With the aging population, greater numbers of senior lawyers will be retiring in the near future. This will increase the importance of knowledge transfer for law firms. However, in order for $\mathrm{KM}$ to be successful, the equation must become: knowledge equals power, so share it and multiply it (Allee, 1997, p.71). KM thus requires a culture that encourages a free-flowing exchange of ideas and acclimatises people to the habits of learning and sharing (Galagan, 1997, p.22). In the view of Bonner (2000), in order for people to be willing to capture, retain and share their hard earned knowledge, organizations must maintain environments that foster cultures of continuous learning and support the integration of internal business functions.

Organizations that produce a supportive culture for KM incorporate many characteristics. Some of these include: a highly supportive management style, a high level of internal trust among employees that fosters sharing of knowledge, and the belief that learning and KM are both critical to the success of the organization (Bonner, 2000, p.38). If senior partners are not willing or able to embrace these concepts, for the reasons described above, it may be necessary to empower younger lawyers to speak about, and implement, KM processes on their behalf.

\subsection{Trust and Loyalty}

As a result of the individualistic nature of law firms, there is currently a lack of sufficient trust and loyalty between colleagues and the firm in order to accommodate effective knowledge transfer. Thus, in addition to establishing a supportive culture, it is also imperative for the organization to develop trust and loyalty among firm members. As Robert Buckman, CEO of Buckman Laboratories said, 'for knowledge sharing to become a reality, you have to create a climate of trust in your organization' (Allee, 1997, p.72). Ardichivili et al. (2003) portray trust in two forms, knowledge-based and institution-based. Knowledge-based trust is a result of social interactions and develops when employees get to know one another, in essence trusting each other. Institution-based trust is having trust in the integrity of the organization and the competence of its members, with the belief that the necessary structures are in place to ensure the trustworthy behaviour of all employees; in other words, the employee trusts the firm.

In order to build trust, a company needs to ensure there is adequate human contact between employees. In order to build personal relationships and networks while also building trust, an environment must go beyond interaction which is facilitated solely through the use of computers (Bender and Fish, 2000). Although, as Smith and Rupp (2002) have observed, computers and 
other technology can increase the speed of knowledge transfer, but they cannot be a substitute for face-to-face contact, voice quality, and other physical cues that help in building trust.

With trust comes loyalty, which occurs when a person is committed and steadfast in his or her allegiance to another person or an organization. In the absence of loyalty, employees will only strive to improve their own position, and not those of other employees or the organization (Smith \& Rupp, 2002, p.251). To build employee loyalty, it is important to provide a clear and carefully developed set of corporate values. The organization should develop an atmosphere where loyalty is a source of competitive advantage within a culture that demonstrates high values of sharing and cooperation. This can be accomplished by rewarding employees when they demonstrate these values and confronting them when they do not. There are many drivers of loyalty. Communication is a main one, along with 5 others (Smith \& Rupp, 2002, p.251):

- Manager's recognition of the importance of personal and family life

- Opportunities for personal growth

- Satisfying customer needs

- Communication about benefits

- Skills keeping pace with job requirements

\subsection{Communities of Practice}

One of the ways to develop trust and loyalty and in return increase the transfer of knowledge is known as Communities of Practice (COP). These are groups of people who, together, search for solutions to common problems, or who share a common area of expertise (Perez, 2002, p.26). People within COP deepen their knowledge and expertise by interacting on an ongoing basis. Three characteristics of COPs are presented by Iverson and McPhee (2002) including: mutual engagement, negotiation of a joint enterprise, and a shared repertoire. Through mutual engagement, or the interaction of members, knowledge is shared. The negotiation of a joint enterprise involves members interacting to give a sense of coherence and purpose to the group. Finally, a shared repertoire is a set of resources (stories, theories, techniques) that can be used by all members. COP allows employees to tap into each other's knowledge, while also enabling those in the organization to continuously enhance their skills and competencies, which has been demonstrated through successful implementations in major companies such as HP and Xerox (Arora, 2002, 243).

Organizations must engage in many steps to ensure a successful COP. They must express a set of norms promoting institutional-based trust, demonstrate that shared knowledge is a norm within the organization, and display trust in their employees. All of these values and actions depict that sharing is a moral obligation (Ardichvili et al., 2003). The development of trust will assure employees that their knowledge will not be misused. Organizations must also establish incentives and rewards for participation in these groups (Perez, 2002, p.62). COP must be cultivated by an organization which occurs in three ways as depicted by Iverson and McPhee (2002): 
- recognizing knowledge and accomplishments rather than to direct or claim credit for them

- ideas and directions are put into words, given persuasive expression and are open to discussion

- collaboration between the group and management

Once implemented successfully, COP will aim to ensure the successful transfer of knowledge throughout the organization.

\subsection{Role of Human Resources}

As discussed above, HR plays a significant role in KM and will continue to do so into the future. HR departments will need to ensure that the 'HR policy is aligned with the knowledge strategy of the organization so employees have a forum where they can freely share and learn from each other' (Arora, 2002, p.242). According to Bender and Fish (2000), by creating a knowledgesharing culture, HR managers enable employees to recognise that their knowledge and expertise is valued, and can encourage employees to communicate and share their knowledge with others. HR managers can help this process by recognizing the existence of groups such as the COPs and facilitating communication within the organization.

HR departments need to provide the opportunity for employees to learn through experience. A key technique employees can use to learn is by monitoring one another. This experience will increase the opportunity to acquire both tacit and explicit knowledge (Argote et al., 2003, p.579). One program the HR department can institute is a mentoring program in which senior employees are expected to help with the learning and development of junior colleagues. To ensure the success of the program, participation can be tied to appraisal and reward systems, demonstrated by the successful implementation of such a system by Ernst \& Young (Dunford, 2000).

\subsection{Motivation and Rewards}

In addition to these numerous responsibilities, the HR department will also be accountable for creating a rewards system that reinforces the transfer of knowledge. Non-monetary rewards play one of the largest roles in motivating individuals to share their knowledge. Social rewards can also have a major impact on employee motivation as strong ties promote the transfer of tacit knowledge since they are more likely to be governed by the norms of reciprocity (Argote et al., 2003, p.575). It is the HR department's responsibility to help facilitate this culture. Bollinger and Smith (2001) observe that reward systems must attempt to reward group effort and not just individual effort, to ensure people will work collectively.

The organization also needs to create a pay-for-knowledge system that emphasises the sharing of knowledge and pays people for sharing. Buckman Laboratories International went so far as to award laptops to those they felt were the most effective knowledge sharers (Stamps, 1997, p.43). Once the reward system has been implemented, the firm needs to ensure it is successful, which can be determined by applying a continuous review system (Arora, 2002, p.254). It can be 
measured through performance feedback, popularity (whether the databases are being used), or by incorporating these objectives into the evaluation of those responsible for managing the firm.

\subsection{Role of Technology}

It cannot be forgotten that technology plays an essential role in the successful implementation of KM. According to Arora (2002), one of the fastest growing technology applications is the use of company intranets and databases. These systems allow employees to share experiences and knowledge, and can be enriched by including contributions from external sources. Organizations can encourage collaboration through e-learning and on-line chats to compliment the person-toperson focus of the strategy. The use of Corporate Portals, which provide access to reports, analysis, queries and other relative information have increased in popularity along with the increase in the use of Groupware systems that are designed to enable communication and sharing of information, such as Lotus Notes, Microsoft Exchange, Domino, etc (Seng et al., 2002, p.145). Another program being implemented is West KM, software designed to interconnect all the documents and information within a business. This program allows the firm to search the system for case laws and other relevant documents stored in the database (Krause, 2003, p.65). Other technologies implemented include teleconferencing and email. In addition, there are a number of specialty software applications, designed specifically for the large law firm, which facilitate the integration of substantive research and document preparation tasks along with communication, timekeeping and accounting information. The CKO and the HR department will be in charge of ensuring that these databases and portals are full of relevant and important but non-repetitive information.

After analysis, all of these six aforementioned areas are vital to ensuring the success of KM within a law firm. Smith and Rupp (2002) suggest that the factors contributing to a successful implementation are creating intellectual connections, networks, a supportive sharing culture and incentives for sharing - without these, a company will be unable to make full use of its potential and existing knowledge sources.

\section{Conclusion}

As a result of the analysis in this paper, the following conclusions have been made regarding the four main objectives.

\section{What is knowledge?}

- Knowledge is defined as what we know

- Data, information and knowledge differ in definition although collaborate in function

- Knowledge is a valuable intangible asset

- Explicit knowledge is easy to articulate and communicate while tacit knowledge is difficult to formalise and communicate

\section{What is knowledge management?}


- It is an emerging discipline in a multi-faceted concept

- It seeks to transform tacit knowledge into explicit knowledge

- Every organization defines and applies KM processes according to their cultural environment, technology, infrastructure

\section{Why is knowledge management important to law firms?}

- To provide the firm with a competitive advantage

- To ensure the growth and sustainability of a firm

- To enable efficiencies

- To capture and document valuable knowledge

What are some solutions and strategies available to law firms to deal with these issues?

- HR will play an important role

- Firms must create a Chief Knowledge Officer and a KM implementation team

- Firms must foster a knowledge sharing culture, through the creation of Communities of Practice and mentoring programs,

- Firm members must be rewarded for sharing

\section{REFERENCES}

Allee, Verna (1997) '12 Principles of Knowledge Management', Training and Development 51.11.

Alvesson, M, Karreman, D, and Swan, J (2002) 'Departures From Knowledge and/or

Management in Knowledge Management', Management Communication Quarterly 16.2.

Ardichvili, A, Vaughn, P, and Wentling, T (2003) 'Motivation and Barriers to Participation In

Virtual Knowledge Sharing Communities Of Practice’ Journal of Knowledge Management 7.1 . 
Argote, L, McEvily, B, and Reagans, R (2003) 'Managing knowledge in organizations: An integrative framework and review’, Management Science 571.

Arora, R (2002) 'Implementing Knowledge Management: A Balanced Score Card Approach', Journal of Knowledge Management 6.3.

Bailey, C, and Clarke, M (2000) 'How do managers use knowledge about knowledge management?' Journal of Knowledge Management 4

Bender, S, and Fish, A (2000) 'The Transfer of Knowledge and The Retention of Expertise: The Continuing Need For Global Assignments.'

Billinger, A, and Smith, R (2001) 'Managing Organizational Knowledge As A Strategic Asset.'

Binney, D (2001) 'The knowledge management spectrum- understating the KM landscape', Journal of Knowledge Management 5.

Bonner, D (2000) 'Enter The Chief Knowledge Officer,' Training and Development 54.2.

Bontis, N (2000), Assessing Knowledge Assets (Kingston: Queen’s University).

Buckler, G (2004), 'Knowledge Management Crucial Tool for Law Firms', $<$ http://mimage.hummingbird.com/alt_content/binary/pdf/collateral/mc/kmcurcia.pdf>.

Carine, H (2003) 'Applying Knowledge Management in Law Firm Alliances.'

Chase, R (1997) 'Knowledge Management Benchmarks,' Journal of Knowledge Management 1.1.

Chatzkel, J 'A conversation with Hubert Saint-Onge,' Journal of Intellectual Capital 1.1.

Curve Consulting (2002), 'Curve Consulting 2001/2 Global Law Firm Knowledge Management Survey Report.'

Dublin, M (2005), 'Creating an Environment in Law Firms Where Knowledge Management Will Work,' <http://www.articlecity.com/articles/legal/article_165.shtml>.

Dunford, R (2000) 'Key Challenges In The Search For The Effective Management of Knowledge In Management Consulting Firms.'

Galagan, P (1997) 'Smart Companies,' Training and Development 51.12.

Garud, R (1997) 'On the distinction between know-how, know-what and know-why,' Advances in Strategic Management.

Gold, A (2001) Towards a Theory of Organizational Knowledge Management Capabilities (North Carolina: University of North Carolina).

Gomes, J (2001) 'Knowledge infrastructures in new product development,' DAI 5.

Gordon, J (1999) 'Intellectual Capital and You,' Training 36.9.

Gottschalk P (2002), 'A Stages of Growth Model for Knowledge Management Technology in

Law Firms', The Journal of Information, Law and Technology (JILT), $<$ http://elj.warwick.ac.uk/jilt/02-2/gottschalk.html $>$.

Helfer, J (1998) ‘Order Out of Chaos: A Practitioner’s Guide To Knowledge Management,' Searcher 6.7.

Horton Jr., F (2000) 'The Wisdom Administrator: Waiting In The Wings,’ Information Outlook 4.9.

Huizing, A (2000) 'Knowledge and Learning, Markets and Organizations: Managing the Information Transaction Space,’ PrimaVera Working Paper Series 18.

Hunter, L, Beaumont, P, and Lee, M (2000) 'Knowledge Management practice in Scottish Law Firms,' Human Resource Management Journal 12.2.

Iverson, J, and McPhee, R (2002) 'Knowledge Management In Communities of Practice,' Management Communication Quarterly 16.2. 
Ives, W, Torrey, B, and Gordon, C (1998) 'Knowledge Management: An Emerging Discipline with a Long History,' Journal of Knowledge Management 1.

Jimes, C, and Lucardie, L (2003) 'Reconsidering the tacit-explicit distinction,' Electronic Journal of Knowledge Management 1.

Kay, S (2003), Cost Value and ROI for knowledge Management in Law Firms.'

Khandelwal, V, and Gottschalk, P (2003), 'A Knowledge Management Survey of Australian Law Firms.'

Krause, J (2003) ‘Organised Intelligence,’ ABA Journal 89.1.

Lambe, P (2003), 'What does KM mean for Law Firms?,' $<$ http://greenchameleon.com/thoughtpieces/kmlaw.pdf>.

Laszlo, K, and Laszlo, A (2002) ‘Evolving knowledge for development,' Journal of Knowledge Management 6.

Madhavan, R (1996), From Embedded Knowledge to Embodied Knowledge (Illinois: University of Illinois).

Martensson, M (2000) 'A critical review of knowledge management as a management tool,' Journal of Knowledge Management 4.

McCampbell, A, Clare, L, and Gitters, S (1999) 'Knowledge management: the new challenge for the $21^{\text {st }}$ century,' Journal of Knowledge Management 3.

McInerney, C (2002) 'Hot Topics: Knowledge Management - A Practice Still Defining Itself,' Bulletin of The American Society For Information Science and Technology 28.3.

Nathanson, A, and Levison, A (2002) 'Differentiate Your Firm with Knowledge Management,' Legal IT.

Neidorf, R (2002) 'Knowledge management: Changing cultures, changing attitudes,' Online.

Nguyen, T (2002), Knowledge Management: Literature Review and Findings (United States: Proquest Information and Learning Company).

Oxbrow, N (2000) 'Skills and Competencies To Succeed In A Knowledge Company,' Information Outlook 4.10.

Perez, E (2002) 'A Second Shot: Knowledge Management Challenge,' Online 26.6.

Rossett, A (1999) 'Knowledge Management Meets Analysis,' Training and Development 53.5.

Seng, C, Zannes, E, and Pace, W (2002) 'The Contributions of Knowledge Management to Workplace Learning,' Journal of Workplace Learning 14.4.

Smith, A, and Rupp, W (2002) 'Communication and Loyalty Among Knowledge Workers: A Resource of The Firm Theory View,' Journal of Knowledge Management 6.3.

Smith, A, and Rupp, W (2003) 'Knowledge Workers: Exploring The Link Among Performance Rating, Pay and Motivational Aspects,' Journal of Knowledge Management 7.1.

Southon, G, Todd, R, and Seneque, M (2002) 'Knowledge Management in three organizations: An exploratory study,' Journal of the American Society for Information Science and Technology 53.12.

St. Clair, G (2001) 'Knowledge Service: Your Company’s Key to Performance Excellence,' Information Outlook 5.6.

Stamps, D (1997) 'Managing Corporate Smarts,' Training 34.8.

Terrett, A (1998) 'Knowledge Management and The Law Firm,' Journal of Knowledge Management 2.1.

Vat, K (2003) 'Toward an Actionable Framework of Knowledge Synthesis in the Pursuit of Learning Organization,’ Information Science. 
Williams, M (2003) Knowledge Management: An Evolving Professional Discipline (New York: Fordham University)

Wilson, T (2002), 'The nonsense of ‘knowledge management,' Information Research 2 $<$ http://InformationR.net/ir/8-1/paper144.html>. 